tivity, $97.6 \%$ specificity and a positive predictive value of $25 \%$ for the detection of hemolysis in neonates. ${ }^{3}$

In addition to having very low predictive ability, the DAT is costly when used as a screening test. US studies of the costs of evaluating neonatal jaundice have reported the cost per test to be US\$17-\$47. . $^{2,5,6}$

Newman and colleagues concluded that the investigation of hyperbilirubinemia should be individualized, with more aggressive investigation of infants with early onset or severe hyperbilirubinemia. ${ }^{6}$ Holtzman has also stressed the need for critical appraisal of strategies intended to identify infants with hyperbilirubinemia.?

In Calgary, routine DAT testing is being phased out in favour of a comprehensive hospital- and community-based transcutaneous bilirubinometry program. We believe that it provides a convenient, rapid, painless, cost-effective and accurate screening assessment for hyperbilirubinemia in the term and near-term neonate, particularly when incorporated into routine well-baby visits by public health nurses. ${ }^{8}$

We believe that the DAT should be reserved for diagnostic purposes in children with early or clinically significant hyperbilirubinemia.

\section{Stephen Wainer}

Assistant Clinical Professor

Jack Rabi

Assistant Professor

Department of Pediatrics

University of Calgary

Martha Lyon

Section Head

Pediatric \& Neonatal Clinical

Biochemistry

Calgary Laboratory Services

Calgary, Alta.

\section{REFERENCES}

I. Sgro M, Campbell D, Shah V. Incidence and causes of severe hyperbilirubinemia in Canada. CMAJ 2006;175(6):587-90.

2. Meberg A, Johansen KB. Screening for neonatal hyperbilirubinemia and $\mathrm{ABO}$ alloimunization at the time of testing for phenylketonuria and congenital hypothyreosis. Acta Paediatr 1998;87:1269-74.

3. Herschel M, Karrison T, Wen M, et al. Evaluation of the direct antiglobulin (Coombs') test for identifying newborns at risk for hemolysis as determined by end-tidal carbon monoxide concentration (ETCOc); and comparison of the Coombs' Test with ETCOc for detecting significant jaundice. J Perinatol 2002;22:34I-7.

4. Dinesh D. Review of positive direct antiglobulin tests found on cord blood sampling. J Paediatr Child Health 2005;4I(9-I0):504-7.

5. Suresh GK, Clark RE. Cost-effectiveness of strategies that are intended to prevent kernicterus in newborn infants. Pediatrics 2004;II4:917-24.

6. Newman TB, Easterling MJ, Goldman ES. Laboratory evaluation of jaundice in newborns: frequency, cost and yield. Am J Dis Child I990;I44:364-8.

7. Holtzman NA. Management of hyperbilirubinemia: quality of evidence and cost. Pediatrics 2004; II4:I086-8.

8. Engle WD, Jackson GL, Stehel EK, et al. Evaluation of a transcutaneous jaundice meter following hospital discharge in term and near-term neonates. $J$ Perinatol 2005;25:486-9o.

DOI:I0.I503/cmaj.I0602I4

\section{[The authors respond:]}

We thank Stephen Wainer and colleagues for their comments on our recent article. ${ }^{1}$ We agree that using any test in isolation, including the Coombs' test, is not the most effective way to identify infants at risk of neonatal hyperbilirubinemia. Our recommendation for Coombs' testing was not for all infants whose mothers had type O+ blood, only for those who had risk factors for hyperbilirubinemia or were already jaundiced at the time of discharge.

Despite existing guidelines from the American Academy of Pediatrics ${ }^{2}$ and the Canadian Paediatric Society ${ }^{3}$ recommending identification of newborns at risk and close follow-up of these infants, our data clearly demonstrate that

Table 1: Use of the direct antibody test to predict the development of hyperbilirubinemia in newborns

\begin{tabular}{lcccc}
\hline Study & PPV (\%) & NPV (\%) & Sensitivity & Specificity \\
\hline Meberg and Johansen $^{2}$ & 12 & 96 & 64 & 65 \\
Herschel et al $^{3 *}$ & 53 & 89 & 15 & 98 \\
Dinesh $^{4} \dagger$ & 23 & 92 & 15 & 95 \\
\hline
\end{tabular}

Note: $\mathrm{PPV}=$ positive predictive value, NPV = negative predictive value.

*Results for infants born to nonsmoking mothers.

†Calculated results from data based on need for phototherapy.

severe neonatal hyperbilirubinemia continues to occur at an alarming rate in Canada. The most common cause in our population was $\mathrm{ABO}$ incompatibility; this needs to be emphasized to pediatricians and primary health care practitioners.

Many strategies have been postulated as being cost-effective in preventing severe neonatal hyperbilirubinemia. We welcome the use of strategies coupling clinical suspicion of risk of hyperbilirubinemia at the time of discharge with close outpatient monitoring. Transcutaneous bilirubinometers, although very useful within a clinical context, may not always serve as a substitute for a serum bilirubin measurement when the bilirubin concentration reaches levels at which phototherapy is required. ${ }^{4,5}$ No reported strategies using transcutaneous bilirubinometers have yet been proven to be cost-effective, ${ }^{6}$ largely because the prevalence of long-term neurological sequelae of severe hyperbilirubinemia is not yet known.

\section{Michael Sgro \\ Douglas Campbell \\ Department of Pediatrics \\ St. Michael's Hospital \\ Vibhuti Shah \\ Department of Pediatrics \\ Mount Sinai Hospital \\ Toronto, Ont.}

\section{REFERENCES}

I. Sgro M, Campbell D, Shah V. Incidence and causes of severe hyperbilirubinemia in Canada. CMAJ 2006;175(6):587-90.

2. American Academy of Pediatrics Subcommittee on Hyperbilirubinemia. Management of hyperbilirubinemia in the newborn infant 35 or more weeks of gestation. Pediatrics 2004;II4:297-316.

3. Fetus and Newborn Committee, Canadian Paediatric Society. Approach to the management of hyperbilirubinemia in term newborn infants. Paediatr Child Health I999;4(2):I6I-4.

4. Engle WD, Jackson GL, Stehel EK, et al. Evaluation of a transcutaneous jaundice meter following hospital discharge in term and near-term neonates. Perinatol 2005;25:486-9o.

5. Danayan KC, Sgro M, McGovern V, et al. Transcutaneous bilirubin measurement in jaundiced newborns. Paediatr Child Health 2006; II(Suppl B):26B.

6. Suresh GK, Clark RE. Cost-effectiveness of strategies that are intended to prevent kernicterus in newborn infants. Pediatrics 2004;114:917-24.

DOI:I0.I503/cmaj.Io60244

In their commentary ${ }^{1}$ on our recent article, ${ }^{2}$ Jeffrey Maisels and Thomas 
Newman accurately pointed out some difficulties in interpreting our data. There is no doubt that data collected through surveillance programs can be incomplete because of the nature of these programs, and this can lead to an underestimation of the number of cases and can limit our ability to thoroughly analyze the factors underlying the findings. Despite this limitation, our study has shown that severe hyperbilirubinemia continues to occur in Canada. The majority of the infants with severe hyperbilirubinemia in our study were readmitted shortly after leaving the hospital, raising the concern that health care providers are missing an opportunity to prevent this condition. Although recommendations from the American Academy of Pediatrics ${ }^{3}$ were recently published, they are currently not being followed or are impractical to apply to newborns.

Given the possibility that introducing routine screening (serum bilirubin measurements, blood group typing and Coombs' testing) may have financial implications such as longer hospital stays for newborns, it is important to understand the burden of illness of severe hyperbilirubinemia and its complications in Canada, namely bilirubininduced neurological dysfunction and kernicterus. Newman and Maisels referenced a Danish case-based report ${ }^{4}$ that estimated the incidence of kernicterus at I in 50000 to I in 60000 live births. It is important to note that this was by no means a systematic review of the Danish population. In our study, half of the infants with severe hyperbilirubinemia were born to nonwhite mothers. ${ }^{2}$ Ethnicity may be a contributing factor to severe hyperbilirubinemia, secondary to a higher incidence of glucose-6-phosphate dehydrogenase deficiency in non-white populations and a delay in recognition of jaundice owing to the babies' darker pigmentation.

We believe that careful assessment of newborns at the time of discharge and consideration of blood group incompatibility and risk of glucose-6- phosphate dehydrogenase deficiency with appropriate follow-up could reduce the incidence of neonatal hyperbilirubinemia and readmission to hospital. A more accurate estimate of the incidence of kernicterus is of paramount importance in order to justify cord blood testing and the measurement of serum bilirubin at the time an infant is discharged from hospital.

\section{Michael Sgro \\ Douglas Campbell \\ Department of Pediatrics \\ St. Michael's Hospital \\ Vibhuti Shah \\ Department of Pediatrics \\ Mount Sinai Hospital \\ Toronto, Ont.}

\section{REFERENCES}

I. Maisels MJ, Newman TB. Surveillance of severe neonatal hyperbilirubinemia: a view from south of the border. CMAJ 2006;175(6):599-60o.

2. Sgro M, Campbell DM, Shah V. Incidence and causes of severe neonatal hyperbilirubinemia in Canada. CMAJ 2006;175(6):587-90.

3. American Academy of Pediatrics. Clinical practice guideline: management of hyperbilirubinemia in the newborn infant 35 or more weeks of gestation. Pediatrics 2004;II4(I):297-316.

4. Ebbesen F. Recurrence of kernicterus in term and near-term infants in Denmark. Acta Paediatr 2000; 89 (I0):1213-7.

DOI:I0.1503/cmaj.1060213

\section{Corrections}

In the meta-analysis of $\beta$-blockers for the treatment of hypertension by Nadia Khan and Finlay McAlister, ${ }^{1}$ there were typographic errors in the numbers reported on the right-hand side of Figs.
$2 \mathrm{~A}$ and $2 \mathrm{~B}$. None of the typographic errors were incorporated in the analyses, and thus there was no effect on the findings or interpretation of the findings. The corrections are summarized here.

Fig. 2A: For the Medical Research Council trial, the denominator for "other drug" should read 4297 (instead of 8654). The overall denominator was I4 708 for the $\beta$-blocker group and I4 638 for the "other drug" group.

Fig. 2B: The overall denominator was 42598 for the $\beta$-blocker group and 44582 for the "other drug" group. The $p$ value for heterogeneity should be 0.08 , not 0.8 . The pooled summary estimate was I.07 (95\% CI I.00-I.I4).

\section{REFERENCE}

I. Khan N, McAlister FA. Re-examining the efficacy of $\beta$-blockers for the treatment of hypertension: a meta-analysis. CMAJ 2006;174(I2):1737-42.

DOI:I0.I503/cmaj.070283

A recent News article ${ }^{1}$ concerning the amount of money Canada spends on foreign aid contained some typographical errors. In fact, Canada spent \$2.719 billion on international aid in 2003/04. This was raised to $\$ 3.237$ billion in 2005. In 2005/06, the federal government spent $\$ 3.637$ billion. We apologize for any inconvenience this error may have caused.

\section{REFERENCE}

I. Kondro W. International aid doldrums. $C M A J$ 2007;176(I):26.

DOI:Io.I503/cmaj.070284

\section{Letters submission process}

CMAJ's enhanced letters feature is now the portal for all submissions to our letters column. To prepare a letter, visit www.cmaj.ca and click "Submit a response to this article" in the box near the top right-hand corner of any CMAJ article. All letters will be considered for publication in the print journal.

Letters written in response to an article published in $C M A J$ are more likely to be accepted for print publication if they are submitted within 2 months of the article's publication date. Letters accepted for print publication are edited for length (usually 250 words) and house style. 